\title{
Magnitude and factors associated with Availability of Adequately lodized Salt at Households of Pregnant Mothers in Wonago district, south Ethiopia
}

Adane Tesfaye ( $\sim$ adanetesfaye2006@gmail.com )

Dilla University https://orcid.org/0000-0001-9860-7764

\section{Research Article}

Keywords: lodine deficiency, field test kit, Wonago District, Ethiopia

Posted Date: October 4th, 2021

DOl: https://doi.org/10.21203/rs.3.rs-952661/v1

License: (c) (1) This work is licensed under a Creative Commons Attribution 4.0 International License.

Read Full License 


\section{Abstract \\ Background}

Salt iodization is the most cost-effective, safe and sustainable strategy to eliminate iodine deficiency disorders. It is especially damaging during pregnancy and in early child hood. Adding iodine to salt provides protection from brain damage due to iodine deficiency for whole populations. However, little was known about the availability of adequately iodized salt in South Ethiopia. The aim of this study was to assess prevalence and factors associated with availability of adequately iodized salt at the households of pregnant mothers in Wonago District, South Ethiopia, 2018.

\section{Methods}

Community-based cross-sectional study was conducted from May 14-29, 2018 in Wonago district. Using a stratified two stage random sampling technique, a total of 604 pregnant mothers were included in the study. The level of salt iodine content was determined using the rapid field test kit, considering a value of $<15$ parts per million (PPM) and $\geq 15$ PPM with the corresponding color chart on the rapid test kit for classification. Multivariable logistic regression model was fitted to identify factors associated with the availability of adequately iodized salt. Adjusted Odds Ratio (AOR) with the corresponding $95 \%$ Confidence Interval $(\mathrm{Cl})$ was calculated to show the strength of association.

\section{Result}

Availability of adequately iodized salt at households of pregnant mothers was $19.9 \%$. House hold head, husband education, average monthly household income and time of salt addition during cooking were independently associated with adequately iodized salt availability. Accordingly, participatory male headed households [AOR=2.1 $(95 \% \mathrm{Cl} 1.08,3.96)$ ], women with an average monthly household income of $\geq 817$ ETB $[A O R=7.3(95 \% \mathrm{Cl} 3.03,17.70)]$ and those who added salt late or after cooking during food preparation $[A O R=2.17(1.08,4.38)]$ were more likely to utilize adequately iodized salt. Conversely, women whose husband had no formal education were less likely $[A O R=0.33(95 \% \mathrm{Cl} 0.11,0.88)]$ to utilize iodized salt.

\section{Conclusion}

Compared to the recommended standard, use of adequately iodized salt among pregnant women is very low. Paternal conditions and household income level are key predictors of use of adequately iodized salt.

\section{Introduction}

lodine deficiency is the world's single greatest cause of preventable mental retardation. It is especially damaging during the early stages of pregnancy and in early child hood. ${ }^{1}$ Iodine deficiency disorders (IDD) 
include stillbirths, abortions, and congenital anomalies; endemic cretinism characterized most commonly by mental deficiency, deaf, mutism, and lessor degrees of neurological defect related to fetal iodine deficiency; impaired mental function in children and adults with goiter associated with subnormal concentrations of circulating thyroxin . 2, 8 Even mild deficiency can cause a significant loss of learning ability - about 13.5 intelligence quotient (IQ) points at population level. ${ }^{3}$ In addition to infringing on the rights of children, iodine deficiency results in a loss of economic productivity. ${ }^{4}$

Prevention of the detrimental effects of inadequate intake of-iodine is of immense importance to global development. It could be the most important achievable international health goal of the decade, exceeding even the impact of global eradication of smallpox in the 1970s. ${ }^{5}$ The World Health Organization (WHO) and United Nations Children's Fund (UNICEF) recommended universal salt iodization since 1993 to end IDDs and their complications.

Globally, close to 2 billion populations (35.2\% of world population) is at risk of iodine deficiency, while one-third lives in areas where natural sources of iodine are low. At least 350 million Africans are at risk of iodine deficiency and its complication. ${ }^{6}$

Universal salt iodization (USI) is recommended as the most cost-effective, safe and sustainable strategy to eliminate iodine deficiency disorders (IDDs). However, only75\% of the household's worldwide use iodized salt. This USI coverage is considered as a dramatic increment compared to the 1990 report, $10 \%{ }^{7}$ Yet iodine deficiency remains a considerable challenge worldwide after decades of efforts to address the problem. $^{8}$

In terms of the region, an optimal iodized salt utilization (90\%) is reported in East Asia and Pacific countries. In sub-Saharan Africa, $64 \%$ of households are using iodized salt, nevertheless the level of utilization widely varies from 10 to $90 \%$ in different countries. For instance, utilization of iodized salt is less than $10 \%$ in Sudan, Mauritania, Guinea-Bissau, and Gambia, whereas, in Burundi, Kenya, Nigeria, Tunisia, Uganda, and Zimbabwe, it is more than $90 \% .{ }^{9}$

To ensure the nutritional health of pregnant women with respect to iodine status, a World Health Organization (WHO) Technical Consultation in 2007 proposed increasing the recommendations for iodine intake of pregnant. The iodine content of household salt should be at least 32 and 51 ppm during early and late pregnancy, respectively. These levels are far above the $15 \mathrm{ppm}$ currently considered to be adequate salt iodine content at the household level. Pregnant women may remain iodine insufficient due to the increased demands for iodine during pregnancy even when other members of a household have achieved iodine adequacy. $8,10,18,19$

In Ethiopia, availability of adequately iodized salt shows a gradual improvement, $4 \%$ in 2000 to $15 \%$ in $2011,23 \%$ in 2014 and 26\% in 2016. Disparities in level of utilization are detected with residence and regions. The rural and urban house hold availability of adequately iodized salt is $30.6 \%$ and $23.8 \%$. South 
Nation Nationalities Peoples Region (SNNPR) is the lowest by adequately iodized salt availability in the country only $13.7 \%{ }^{11}$

Ethiopia is a salt producing state, endorsed mandatory salt iodization program and is working with partners, United Nations Children's Fund (UNICEF),Global Alliance for Improved Nutrition (GAIN) and Micronutrient Initiatives, to reach utilization of iodized salt>90\% thereby to mitigate iodine deficiency. ${ }^{12}$ But, still only $23.2 \%$ of the households use adequately iodized salt. In addition, iodine deficiency remains the major public health problem among pregnant women and school children. ${ }^{13}$

There were no studies regarding availability and factors associated with adequately iodizeds in Wonago District. Therefore, this study aimed to determine magnitude and factors associated with availability of adequately iodized salt at households of pregnant mothers in Wonago district, South Ethiopia.

\section{Material And Methods}

\section{Study setting and design}

A community-based cross-sectional quantitative study method was applied from May 14-29/2018 in Wonago district. The study was carried out in six randomly selected kebeles of Wonago district which is located $13 \mathrm{~km}$ from Dilla (administrator city of Gedeo zone) and $377 \mathrm{~km}$ from Addis Ababa (capital city of Ethiopia). The district has 152,609(female=76,686 and male=75,923) population and households 31,145. Wonago district has 21 kebeles (the smallest administration unit in Ethiopia). ${ }^{14}$

\section{Study population}

Households with pregnant mother who were apparently healthy during the study period were included in the study and severely ill to respond or with difficulty in speech or listening were excluded. The sample size of 604 households of pregnant women was determined by using formula for estimating single population proportion and with the following assumptions to obtain the optimum sample size: $\mathrm{P}=$ proportion of households with adequately iodized salt $39 \%,{ }^{15} \mathrm{Z}=$ reliability coefficient $=1.96, d=5 \%$ margin of error and, design effect $(D E)=1.5$, non-response rate $=10 \%$

\section{Data collection instruments and procedure}

A structured interviewer-administered questionnaire was used to collect survey data. The questionnaire was developed by the investigator after reviewing literatures They were initially prepared in English then translated in to the local language (Amharic and Gedeo-fa) and finally, back translated to English to maintain consistency. A total of six data collectors (six diploma nurses) and one supervisor (BSc nurse) were recruited for the study. Daily supervision and feedback was carried out by the investigator and supervisors during the entire data collection period. A table spoon of salt was taken from each house hold and iodine Rapid Test Kit (MBI-International) was used to determine the level of salt iodine content. The small cup in the kit was filled with salt, and made the cup surface flat. Two drops of test solution 
from white ampoule were added to the surface of the salt by piercing the white ampoule with a pin and gently squeezing the ampoule.

The iodine content in the salt was determined within one minute by comparing the color change on the salt with the color chart. The value parts per million (PPM), $<15$ PPM and $\geq 15$ PPM with the corresponding color chart on the rapid test kit was used to classify the level of iodine in the sampled salt. If no color appears (after $1 \mathrm{~min}$ ), 5 drops of the recheck solution from red ampoule were added to a fresh salt sample and followed by 2 drops of test solution on the same salt sample. A comparison was done with the color chart indicators for salt iodine content. Finally, Availability of adequately iodized salt was considered when the household sampled salt had $\geq 15 \mathrm{ppm}$ iodized salt. Otherwise, it was classified to inadequately iodized or non-iodized salt. ${ }^{12,19}$

\section{Data Processing and Analysis}

Each questionnaire was checked for completeness and consistency by supervisors. Data was exported from epi-data version 3.1 to SPSS version 20.0 for analysis. It was summarized with tables and figures. To identify factors associated with availability of adequately iodized salt, each variable was assessed independently whether a predictor of availability of adequately iodized salt or not. First, variables were tested using bivariate analysis. Variables which were associated in bivariate analysis were tested in the final multivariate analysis to see their association with availability of adequately iodized salt.

\section{Results}

\section{Socio-economic and demographic characteristics}

Majority of the respondents $310(52.7 \%)$ were in the age group of 25-34 years and their mean (SD \pm 5.40$)$ age was 26.7 years. $514(87.4 \%)$ were from rural area .More than three-fourth $(77.7 \%)$ households were headed by men (husbands). Majority of the respondents (54.4\%) had family size greater than five. Slightly less than half or $286(48.6 \%)$ had not formal education, but three-fourth (74.5\%) of husbands of these women had at least some form of formal education. More than ninety five in hundred $(96.30 \%)$ respondents were housewife (Table 1).

Knowledge of respondents towards iodized salt

237 (40.3\%) had good knowledge. Slightly less than half 275 (46.8\%) of the respondents reported that they had heard about iodized salt. The main source of information being health worker 105(38.2\%) followed by TV/radio 81(29.5\%) and family member 55(20\%). Even if they had had information, 166 $(60.4 \%)$ of the respondents reported that they didn't use iodized salt because it is expensive 155 (93.4\%). (Table 2)

Source and type of iodized salt 
$510(86.7 \%)$ households used unpacked salt during the study in the district. Majority $436(74.1 \%)$ of the respondents purchased salt from market for consumption. (Table 3)

\section{Handling and utilization practices}

Out of the respondents, only $60(10.2 \%)$ had proper practice. Majority $300(51.0 \%)$ of the respondents reported that they can't identify iodized salt. Slightly more than one-fourth $155(26.4 \%)$ of the respondents said iodized salt is more white than else. Only slightly more than one-fifth $133(22.6 \%)$ of the respondents can identify iodized salt by reading the logo. Out of the respondents, $248(42.2 \%)$ added salt early/at the middle of cooking during food preparation (table 4).

Availability of adequately iodized salt at households of pregnant women

$117(19.9 \%)$ had adequately iodized salt (salt iodine content $\geq 15$ PPM) but $471(80.1 \%)$ sampled households had inadequately iodized salt (salt iodine content $<15$ PPM). According to residence, adequately iodized salt availability was $33.8 \%$ ( 25 households out of 74 sampled households) in Urban and $17.9 \%$ (92 households out of 514 sampled households) in rural areas of Wonago district during the study period. (Figure 1)

Factors associated with availability of adequately iodized salt

Predictor variables of socio-demographic, maternal knowledge, source and type of salt, and handling and utilization practices were assessed independently.

Both women and husband (participatory) headed households were twice more likely to utilize adequately iodized salt compared with husband only headed households [AOR=2.10 $95 \% \mathrm{Cl}(1.08,3.96)]$. Similarly, Pregnant women whose average monthly household income was between 816 and 1634 ETB were 7.32 times $[A O R=7.3295 \% \mathrm{Cl}(3.03,17.70)]$ more likely to utilize adequately iodized salt compared with whose average monthly household income was 816 ETB or less.

However, pregnant women who had husbands with no formal education (no formal schooling) were less likely to use adequately iodized salt by $67 \%$ [AOR $=0.3395 \% \mathrm{Cl}(0.11,0.88)]$ compared with counter parts.

Respondents who added salt late or after cooking during food preparation were twice [AOR=2.17(1.08, 4.38)] more likely to utilize adequately iodized salt compared with who added salt early or at the middle of cooking. (Table 5) and (Table 6)

\section{Discussion}

The study aimed to assess the availability and predictors of using adequately iodized salt among pregnant women in one of the rural cash crop (coffee) producing areas of Ethiopia. Accordingly, results showed that utilization of adequately iodized salt among pregnant women was very low. There were 
several maternal, paternal and household factors identified as key predictors of use or non-use of products.

The availability of adequately iodized salt ( $\geq 15 \mathrm{ppm})$ was found to be only $19.9 \%$ [95\% $\mathrm{Cl}(16.70 \%$, $23.13 \%)$ ] which was far lower than the WHO recommendation according to which greater than $90 \%$ of households should utilize adequately iodized salt to eliminate IDD. ${ }^{20}$ However, the present study finding was higher than the regional (SNNPR) $13.7 \%,{ }^{20}$ a study conducted in Niger $6.2 \%,{ }^{21}$ Homoe, Ghana $16.5 \%$ , 24 Northern Ethiopia 6\%, 22 and Lalo Assabi, West Ethiopia 8.7\%. ${ }^{23}$ This might be due to different socioeconomic characteristics and time sequence of the study area and referenced area.

This finding was lower than the national $26 \%,{ }^{11}$ a study conducted in Jalisco, Mexico $24 \%,{ }^{24}$ Kolkata, India $34 \%,{ }^{25}$ Bareilly, India 42\%, ${ }^{26}$ Volta, Ghana $24.6 \%,{ }^{10}$ Costal province, Kenya $26.2 \%,{ }^{6}$ Dabat, North West Ethiopia 33.2\%, ${ }^{27}$ Gondar, North West Ethiopia28.9\%, ${ }^{17}$ Laelay Machew 33\%, ${ }^{28}$ and Gobba town, South East Ethiopia 30\% ${ }^{29}$ This might be due to different socio-demographic characteristics, sources and type of salt used. Another possible explanation is the difference in practices and knowledge level of the study and referred areas. For example, using packed salt, dry area salt storage place, salt container with cover and unexposed to sunlight in Laelay Maychew was $27.3 \%, 91.8 \%, 92.3 \%$ and $97.3 \%$ but in the study area, it was $13.3 \%, 85.5 \%, 83.2 \%$, and $83.8 \%$ respectively.

In this study, Households whose head were both husband and wife (participatory) was significantly associated with adequately iodized salt utilization. The possible explanation could be free flow of ideas between the partners exposed to information and commonness. Besides, husband education was significantly associated with adequately iodized salt utilization. This might be due to education and household discussion influences nutritional knowledge. This finding was similar with a study conducted in Dara district, North West Ethiopia. ${ }^{30}$

In this study, average monthly household income was significantly associated with adequately iodized salt utilization. Pregnant mothers whose average monthly household income was between 816 and 1634 ETB were 7.3 times [AOR=7.32 95\% $\mathrm{Cl}(3.03,17.70)]$ more likely to utilize adequately iodized salt compared with whose average monthly household income was 816 ETB or less. The possible explanation could be those who have better income can access and buy what they prefer-recent batch iodized salt. Another possible reason could be those with lower income may source their salt from market which lost its iodine content through exposure to light. This finding was in line with a study conducted in Wolayta Sodo zuriya district, ${ }^{31}$ and Ghana. ${ }^{32}$

The study showed that time of iodized salt addition during cooking was significantly associated with adequately iodized salt utilization. Respondents who added salt late or after cooking during food preparation were twice $[A O R=2.17(1.08,4.38)]$ more likely to utilize adequately iodized salt compared with who added salt early or at the middle of cooking. lodized salt should be added to meal late or after cooking in order not to lose the iodine content of the salt through heating. This finding was consistent 
with a study done in Ada district, Oromia. ${ }^{15}$ The possible explanation for this could be due to similarity in household practices.

Compared to the recommended standard, use of adequately iodized salt among pregnant women is very low. Household head (participatory), husband education and household income level are key predictors of use of adequately iodized salt.

\section{Limitation of the study}

This study used rapid field test kit to measure salt iodine level from salt samples which didn't include titration and urinary iodine concentration of pregnant mothers.

\section{Conclusion}

The findings showed that only $19.9 \%$ households of pregnant mothers had adequately iodized salt which was very low compared to the recommended value ( $90 \%$ \& above) to control iodine deficiency disorders. Adequately iodized salt availability at household level was influenced by factors like household head, educational level, average monthly household income and time of salt addition during cooking in Wonago district.

Based on finding of the study, the following recommendations were made:

The SNNPR Health bureau, Gedeo Zone Health Department and Wonago District Health Office should Strengthen, cooperate and monitor supply chain, educational program to influence utilization of adequately iodized salt at household level in the study area. Health care professionals should teach the community towards good handling and practice of iodized salt through behavior change communication in Wonago district and further study should be conducted considering titration and urinary iodine concentration.

\section{Declarations}

\section{Ethics approval and consent to participate}

Ethical clearance was obtained from the Institutional Review Board (IRB) of Dilla University, College of Health Science and Medicine. Letters of permission were gained from Gedio Zone Health Department and Wonago District Health Office. The local authorities were informed about the study objectives. Informed consent was obtained from participants involved in the study.

\section{Acknowledgments}

We would like to express our heartfelt gratitude to study participants; data collectors and supervisors. Moreover, we would like to give our appreciation for Dilla University College of health sciences and 
referral Hospital especially for public health department, for their effort and ongoing coordination for the effectiveness of this study.

\section{Authors' contributions}

MA involved in the design, selection of articles, statistical analysis and manuscript writing. TAZ and ATA also involved in analysis and manuscript preparing and editing. All authors read and approved the final draft of the manuscript.

\section{Disclosure}

The author reports no conflicts of interest in this work.

\section{Abbreviations}

ANC: Ante Natal Care

CIDA: the Canadian International Development Agency

CIF: Central lodization Facility

GAIN: Global Alliance for Improved Nutrition

EDHS: Ethiopia Demographic and Health survey

ETB: Ethiopian Birr

FAO: Food Aid Organization

FGD: Focus Group Discussion

HEWs: Health Extension Workers

ICCIDD: International Council for Control of lodine Deficiency Disorders

IQ: Intelligence Quotient

IDD: lodine Deficiency Disorder

IRB: Institutional Review Board

NNP: National Nutrition Program

PPM: parts per million

PPS: Proportional to Population Size 
SNNPR: South Nation Nationalities People Region

UNICEF: United Nation International Children's Fund

USD: United States Dollar

USI: Universal Salt lodization

WHO: World Health Organization

\section{References}

1. Jooste eta. lodine nutrition in Africa:an update for 2014 sight and life,27(3),50-55. 2013;

2. Zimmermann et al. lodine deficiency disorders. The Lancet. 2008 oct 4:372(9645):1251-62.

3. Bogale et al. lodine status and cognitive function of women and their five year old children in rural sidama,southern Ethiopia.East Afr.J.public health.2009;6(3):296-9.

4. Santiago Fernandez et al. Intelligence quotient and iodine intake: a cross-sectional study in children. The journal of clinical endiocronology and metabolism. 2004 Aug: 1:89(8):3851-7.

5. Micronutrient Initiative ICCIDD U. Monitoring univerisal salt iodization programs PAMM/MI/ICCIDD,Atlanta,GA,US;1995.

6. Li M EC. The changing epidemiology of iodine deficiency.Nature Reviews Endocronology.2012 JUl;8(7):434.

7. Anderson M de Benoist B R. Epidemiology of iodine deficiency: salt iodization and iodine status.Best practice and research clinical endocronology and metabolism.2010 Feb 1;24(1):1-1.

8. WHO,UNICEF I. Assessment of iodine deficiency disorders and monitoring their elimlnation.Aguide of program managers. 3rd ed. Geneva(Siwtzerland) WHO 2007. :1-107.

9. WHO,UNICEF I. Assessment of iodine deficiency disorders and monitoring their elimination.2nd ed.Geneva(Sitzerland):WHO,2007.

10. Moleti M Trimarchi F V. doubts and concerns about isolated maternal hypothyroxinemia.Journal of thyroid research.2011.

11. Survey DEH. Ethiopia Demographic and Health Survey 2016. Addis Ababa,Ethiopia and Calverton,Maryland,USA. Central Statistical Agency[Ethiopia] and ORC Macro. 2017.

12. Gidey B Alemu K Atinafu A Kifle M TYSH. Availability of Adequate lodized Salt at Household Level and Associated Factors in Rural Communities in Laelay Maychew District, Northern Ethiopia: a crosssectional study.Journal Nutrition Health Sciences. 2015 Feb 9:2(1):1. 2(1):1-9.

13. Negeri Z Gobena T Rajesh P KM. Determining magnitude of iodine deficiency and its associated risk factors among pregnant women visiting Jimma Univerisity Specialized Hospital for antenatal care.World J Med Sci. 2014:2:1-16. 
14. Makokha E. Factors contributing to iodine deficiency in Coast province of Kenya:European Journal of Research in Medical Sciences.2015: 3.

15. Sayed S. lodine and the "Near" Eradication of Cretinism.2018: 135(4).

16. WinAz. Micronutrient deficiency in early childhood can lower country GDP:The Myanmar example,Nutrition.2016: 32(1):38-40.

17. Mehmood. Factors affecting sustainable iodine deficiency elimination in pakistan.2016: 27(6):24957.

18. WHO, UNICEF I. Guideline fortification of food grade salt with iodine for the prevention and control of iodine deficiency disorder.2014. Geneva;

19. Kabir. lodine status in pregnancy and household salt iodine content in rural banglalesh.2010.

20. FMOH E. Remarkable progress against iodine deficieny in Ethiopia.2016.

21. Emiru S. Iodine deficiency in school age children 7-12 years and Associated factors i Akaki-kality subcity of Addis Ababa.2016.

22. Indian jornal of medical specialists. Iodine Nutrition of pregnant women in India:evidence significant iodine deficiency.2010.

23. Shaw A. A Study on the Effect of lodine Content of Salt Samples on the lodine Nutrition Status of Pregnant, Lactating and Healthy:IJRSB.2014: 2(6):17-25.

24. Edita Z. lodine nutrition among pregnant women in B. M. C.2016.

25. Upadhyay R. lodized salt at households and retail shops in a rural community of Northern India:Research Gate.2012. (January).

26. Aaron. Coverage of Adequately lodized Salt Is Suboptimal and Rice Fortification Using Public Distribution Channels Could Reach Low-Income Households:PLOS|ONE.2016::1-15.

27. Atul K. Status of Consumption of lodized Salt in Rural Population in District Bareilly,U.P.India:Int.Curr.Microbiol.App.Sci.2015. 4(7):585-92.

28. Mukhopadhyay. Limited Access to lodized Salt among the Poor and Disadvantaged in North 24 Parganas District of West Bengal,India:J HEALTH POPULATION NUTR.2010: 28(4):369-74.

29. Rahman A. Comparative Study of Urban and Rural Salts for lodine Content Dhaka,Banglash.2015.

30. Team U survey. Household coverage with Adequately iodized salt varies greately between countries and by resident types National coverage survey:The Jornal of Nutrition.2017: 147:1004-14.

31. Kweku. Availablity of adequete iodized salt at household level and associated factors to iodized salt use among households in rural communities in the hooe municipality of Ghana.2017: 3(5):42-51.

32. Abebe Zegeye et al. Availability of adequately iodized salt in Northwest Ethiopia: a cross-sectional study:Archives of Public Health.2017: :1-9.

\section{Additional Files}


- The datasets used and/or analysed during the current study are available from the corresponding author on reasonable request.

\section{Tables}

Table 1: Socio-demographic characteristics of respondents on availability of adequately iodized salt at households of pregnant women in Wonago district, South Ethiopia, 2018 


\begin{tabular}{|c|c|c|}
\hline variable & Frequency & percent \\
\hline \multicolumn{3}{|c|}{ Age in years } \\
\hline $15-24$ & 221 & 37.6 \\
\hline $25-34$ & 310 & 52.7 \\
\hline $35-45$ & 57 & 9.7 \\
\hline Total & 588 & 100 \\
\hline \multicolumn{3}{|l|}{ Residence } \\
\hline Rural & 514 & 87.4 \\
\hline Urban & 74 & 12.6 \\
\hline Total & 588 & 100 \\
\hline \multicolumn{3}{|l|}{ Religion } \\
\hline Protestant & 521 & 88.6 \\
\hline Orthodox & 53 & 9 \\
\hline Islam & 14 & 2.4 \\
\hline total & 588 & 100 \\
\hline \multicolumn{3}{|l|}{ Ethnicity } \\
\hline Gedeo & 499 & 84.9 \\
\hline Oromo & 53 & 9 \\
\hline Gurage & 15 & 2.6 \\
\hline Amhara & 12 & 2 \\
\hline Other & 9 & 1.5 \\
\hline Total & 588 & 100 \\
\hline \multicolumn{3}{|c|}{ Head of household } \\
\hline Husband & 457 & 77.7 \\
\hline Both & 131 & 22.3 \\
\hline Total & 588 & 100 \\
\hline \multicolumn{3}{|l|}{ Family size } \\
\hline$\leq 5$ & 268 & 45.6 \\
\hline$>5$ & 320 & 54.4 \\
\hline
\end{tabular}




$\begin{array}{lll}\text { Total } & 588 & 100\end{array}$

Educational status of mothers

\begin{tabular}{lll} 
Not educated & 286 & 48.6 \\
\hline Educated & 302 & 51.4 \\
\hline Total & 588 & 100 \\
\hline Educational status of husband & & \\
\hline Not educated & 150 & 25.5 \\
\hline Educated & 438 & 74.5 \\
\hline Total & 588 & 100 \\
\hline Occupational status of mother & & \\
\hline Housewife & 566 & 96.3 \\
\hline Employee & 22 & 3.7 \\
\hline Total & 588 & 100 \\
\hline Average monthly HH income & & \\
\hline$<817$ ETB & 308 & 52.4 \\
\hline $817-1634$ ETB & 195 & 33.2 \\
\hline$\geq 1635$ ETB & 85 & 14.4 \\
\hline Total & 588 & 100 \\
\hline
\end{tabular}

$\mathrm{HH}=$ Household, $\mathrm{ETB}=$ Ethiopia Birr

Table 2: Knowledge of respondents on availability of adequately iodized salt at households of pregnant women in Wonago district, South Ethiopia, 2018 


\section{Respondents knowledge}

$\begin{array}{ll}\text { Good knowledge } & 237\end{array}$

Poor knowledge

Total

\section{Ever heard about iodized salt}

Yes

275

46.8

No

313

53.2

Total

588

100

\section{Main source of information}

TV / radio

81

13.8

Health worker

105

17.9

Family member

55

9.4

School

21

3.6

Printed material

13

2.2

No information

313

53.2

Total

588

100

\section{Use of iodized salt right now}

Yes

No

166

60.4

Total

275

100

Reason for not using iodized salt

Expensive

155

93.4

Not accessible

11

5.4

Total

166

100

Cause of goiter

lodine deficiency

169

28.7

Hereditary

164

27.9

Water(rain) 
Don't know

Total

\section{Disorders of lack of iodine}

Mental retardation 25 169

12

12

370 588

322

266

588

4.3

28.7

2.0

2.0

62.9

100

\section{Goiter is preventable}

Yes

No

Total
54.8

45.2

100

Table 3: Source and type of salt of respondents on availability of adequately iodized salt at household of pregnant women in Wonago district, South Ethiopia, 2018.

\begin{tabular}{lll} 
Variable & Frequency & Percent \\
\hline Source & & \\
\hline Market & 436 & 74.1 \\
\hline Shop/pharmacy & 152 & 25.9 \\
\hline Total & 588 & 100 \\
\hline Type & & \\
\hline Unpacked & 510 & 86.7 \\
\hline Packed & 78 & 13.3 \\
\hline Total & 588 & 100
\end{tabular}


Table 4: Practices of respondents on availability of adequately iodized salt at pregnant women households in Wonago district, South Ethiopia, 2018 


\begin{tabular}{|c|c|c|}
\hline Variable & Frequency & Percent \\
\hline \multicolumn{3}{|l|}{ practice } \\
\hline Proper practice & 60 & 10.2 \\
\hline Improper practice & 528 & 89.8 \\
\hline Total & 588 & 100 \\
\hline \multicolumn{3}{|c|}{ Method of identifying iodized salt } \\
\hline More white & 155 & 26.4 \\
\hline Reading the logo & 133 & 22.6 \\
\hline Don't know & 300 & 51.0 \\
\hline Total & 588 & 100 \\
\hline \multicolumn{3}{|c|}{ Distance on foot to buy salt } \\
\hline$\leq 1$ hour & 519 & 88.3 \\
\hline$>1$ hour & 69 & 11.7 \\
\hline Total & 588 & 100 \\
\hline \multicolumn{3}{|c|}{ Salt added during food preparation } \\
\hline Late/after cooking & 340 & 57.8 \\
\hline Early/middle of cooking & 248 & 42.2 \\
\hline Total & 588 & 100 \\
\hline \multicolumn{3}{|l|}{ Salt exposed to light } \\
\hline Yes & 95 & 16.2 \\
\hline No & 493 & 83.8 \\
\hline Total & 588 & 100 \\
\hline \multicolumn{3}{|l|}{ Place of salt in household } \\
\hline Fire/moist area & 85 & 14.5 \\
\hline Dry area & 503 & 85.5 \\
\hline Total & 588 & 100 \\
\hline \multicolumn{3}{|l|}{ Salt container cover } \\
\hline With cover & 489 & 83.2 \\
\hline No cover & 99 & 16.8 \\
\hline
\end{tabular}


Total

588

100

Duration of salt storage

$\leq 2$ months

518

70

588

471

80.1

Inadequate iodine level

Adequate iodine level

Total
117

588
88.1

11.9

100

\section{$\mathrm{HH}=$ Household, RTK=Rapid Test Kit}

Table 5: Associated factors of availability of adequately iodized salt at households of pregnant women in Wonago district, South Ethiopia, 2018 
Salt iodine content

variable

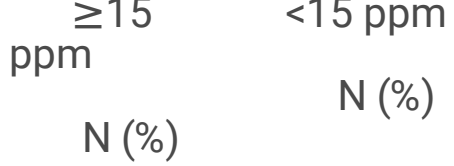

Household head

\begin{tabular}{lllll} 
Husband & $55(12 \%)$ & $402(88 \%)$ & 1 & 1 \\
\hline Both & $62(47.3 \%)$ & $69(52.7 \%)$ & $6.57[4.21,10.24]^{\star \star \star}$ & $\mathbf{2 . 1 0}[1.08,3.96]^{*}$
\end{tabular}

Mother education

\begin{tabular}{lllll} 
Not educated & $27(9.4 \%)$ & $259(90.6 \%)$ & 1 & 1 \\
\hline Primary $(1-8)$ & $44(18.7 \%$ & $191(81.3 \%)$ & $2.21[1.32,3.69]^{\star \star}$ & $1.16[0.56,2.38]$ \\
\hline Secondary\& above & $46(68.7 \%)$ & $21(31.3 \%)$ & $\begin{array}{l}21.01[10.96, \\
40.28]^{\star \star \star}\end{array}$ & $1.53[0.54,4.38]$
\end{tabular}

\section{Husband education}

Not educated
Educated
Mother occupation

\begin{tabular}{lllll} 
employee & $16(72.75)$ & $6(27.3 \%)$ & $12.28(4.69,32.15)^{\star \star \star}$ & $0.75(0.17,3.42)$ \\
\hline Not employee & $101(17.8 \%)$ & $465(82.2)$ & 1
\end{tabular}

Husband occupation

\begin{tabular}{lllll}
\hline farmer & $37(11.81 \%)$ & $277(88.2 \%)$ & 1 \\
\hline merchant & $35(30.70 \%)$ & $79(69.30 \%)$ & $3.32(1.96,5.61)^{\star \star \star}$ & $0.73(0.35,1.53)$ \\
\hline employee & $40(58.8 \%)$ & $28(41.20 \%)$ & $10.7(5.9,19.3)^{\star \star \star}$ & $0.43(0.16,1.16)$ \\
\hline Daily labor & $5(5.4 \%)$ & $87(94.60 \%)$ & $0.43(0.16,1.13)$ & $0.38(0.12,1.16)$ \\
\hline Monthly HH income & & & & \\
\hline$<817$ ETB & $7(2.3 \%)$ & $301(97.7 \%)$ & & $\mathbf{1}$ \\
\hline 817-1634 ETB & $44(22.6 \%)$ & $151(77.4 \%)$ & $12.53[5.51,28.48]^{\star \star \star}$ & $\mathbf{7 . 3 3}[\mathbf{3 . 0 3}, \mathbf{1 7 . 7 0}]^{\star \star \star}$ \\
\hline$>1634$ ETB & $66(77.6 \%)$ & $19(22.4 \%)$ & $149.36[60.33$, & $\mathbf{5 1 . 8 1}[\mathbf{1 6 . 9 2 , 1 5 8 . 6 3}]^{\star \star \star}$ \\
\hline
\end{tabular}

\section{Type of salt}




\begin{tabular}{lllll} 
Unpacked & $64(12.5 \%)$ & $446(87.5 \%)$ & 1 \\
\hline Packed & $53(67.9 \%)$ & $25(32.1 \%)$ & $14.77[8.58,25.43]^{\star \star \star}$ & $1.47[0.57,3.75]$
\end{tabular}

\section{Source of salt}

\begin{tabular}{lllll} 
Market & $43(9.9 \%)$ & $393(90.1 \% 0$ & 1 \\
\hline Shop/pharmacy & $74(48.7 \%)$ & $78(51.3 \%)$ & $8.67[5.54,13.56]^{\star \star \star}$ & $1.33[0.63,2.86]$
\end{tabular}

\section{Distance on foot to buy}

\begin{tabular}{lllll}
$\leq 1$ hour & $115(22.2 \%)$ & $404(77.8 \%)$ & 1 \\
\hline$>1$ hour & $2(2.9 \%)$ & $67(97.1 \%)$ & $0.11[0.03,0.44]^{\star \star}$ & $2.78[0.59,13.02]$
\end{tabular}

\section{Salt added}

Early/middle of $\quad 31(9.1 \%) \quad 309(90.9 \%)$
cooking

$\begin{array}{lllll}\text { Late/after cooking } \quad \text { 86(34.7\%) } & \text { 162(65.3\%) } & 5.29[3.37,8.32]^{\star \star \star *} & \mathbf{2 . 1 7}[\mathbf{1} . \mathbf{0 8}, \mathbf{4} . \mathbf{3 8}]^{\star}\end{array}$

\section{Place of storage}

\begin{tabular}{lllll} 
Fire/moist area & $1(1.2 \%)$ & $84(98.8 \%)$ & $0.04[0.005,0.29]^{\star \star}$ & $0.22[0.02,2.18]$ \\
\hline Dry area & $116(23.1 \%)$ & $387(76.9 \%)$ & 1
\end{tabular}

\section{Salt container}

\begin{tabular}{lllll}
\hline No cover & $1(1 \%)$ & $98(99 \%)$ & $0.03[0.005,0.024]^{\star \star}$ & $0.13[0.01,1.59]$ \\
\hline With cover & $116(23.7 \%)$ & $373(76.3 \%)$ & 1 \\
\hline HH storing time & & & & 1 \\
\hline$\leq 2$ months & $112(21.6 \%)$ & $406(78.4 \%)$ & & 1 \\
\hline$>2$ months & $5(7.1 \%)$ & $65(92.9 \%)$ & $0.28[0.11,0.71]^{\star \star}$ & $0.49[0.13,1.92]$
\end{tabular}

$\mathrm{HH}=$ household, RTK=Rapid Test Kit, ${ }^{*}=\mathrm{p}<0.05, * *=p<0.01, * \star *=p<0.001$

\section{Figures}


Conceptual frame work extracted from different literatures

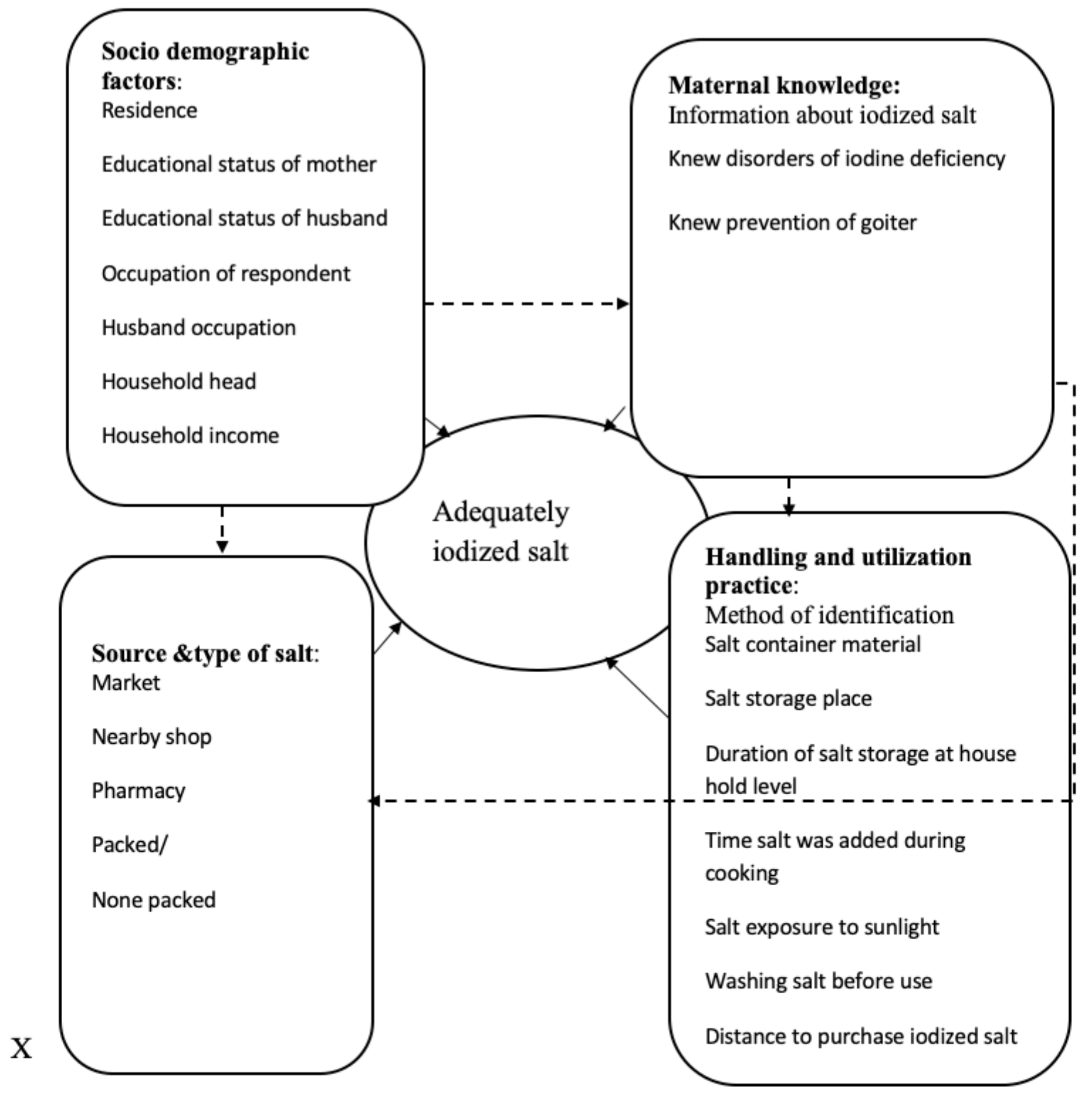

Figure 1

Schematic presentation of conceptual framework showing factors associated with availability of adequately iodized salt at households of pregnant women, extracted from different literatures, Wonago district, 2018. 